BMJ Open Sport \& Exercise Medicine

\section{Disparities in baseline neurocognitive testing for student concussion management in Massachusetts high schools}

To cite: Campbell J, Howland J, Hess C, et al. Disparities in baseline neurocognitive testing for student concussion management in Massachusetts high schools. BMJ Open Sport \& Exercise Medicine 2020;6:e000752. doi:10.1136/ bmjsem-2020-000752

Accepted 9 May 2020

\section{Check for updates}

(c) Author(s) (or their employer(s)) 2020. Re-use permitted under CC BY-NC. No commercial re-use. See rights and permissions. Published by BMJ.

${ }^{1}$ Department of Emergency Medicine, Boston University Medical Center, Boston, Massachusetts, USA ${ }^{2}$ Injury Prevention Center, Boston Medical Center, Boston, Massachusetts, USA

${ }^{3}$ Department of Counseling \& School Psychology, University of Massachusetts Boston, Boston, Massachusetts, USA ${ }^{4}$ Department of Biostatistics, Boston University School of Public Health, Boston, Massachusetts, USA ${ }^{5}$ Department of Neurology, Boston University School of Medicine, Boston, Massachusetts, USA

Correspondence to Dr Julia Campbell; jkcampbe@bu.edu

\section{ABSTRACT}

Purpose There is evidence of socioeconomic disparities with respect to the implementation of student-sports concussion laws nationally. The purpose of this study was to examine school sociodemographic characteristics associated with the provision of computerised baseline neurocognitive testing (BNT) in Massachusetts (MA) high schools, and to assess whether the scope of testing is associated with the economic status of student populations in MA.

Methods A cross-sectional secondary analysis of surveys conducted with MA athletic directors $(n=270)$ was employed to investigate school characteristics associated with the provision of BNT. Correlation and regression analyses were used to assess whether the scope of testing is associated with the economic status of student populations in MA.

Results The scope of BNT was independently associated with the economic disadvantage rate (EDR) of the student population $(\beta=-0.02, p=0.01)$; whether or not the school employs an athletic trainer (AT) $(\beta=0.43, p=0.03)$; and school size $(\beta=-0.54, p=0.03)$. In a multivariable regression model, EDR was significantly associated with the scope of baseline testing, while controlling for AT and size $\left(\beta=-0.01, p=0.03\right.$, adj- $\left.R^{2}=0.1135\right)$.

Conclusion Among public high schools in MA, disparities in the provision of BNT for students are associated with the economic characteristics of the student body. Schools that have a greater proportion of low-income students are less likely to provide comprehensive BNT. The clinical implications of not receiving BNT prior to concussion may include diminished quality of postconcussive care, which can have short-term and long-term social, health-related and educational impacts.

\section{INTRODUCTION}

Concussion, or mild traumatic brain injury, is common among school-aged youth and results from a direct or indirect impact to the head or neck. ${ }^{1}$ Incidence estimates among children and adolescents under age 17 range from 1 to 2 million brain injuries a year. ${ }^{2}$ An estimated 300000 of these are sports related. ${ }^{3}$ Youth with concussion can experience
New findings and clinical implications

- In Massachusetts public high schools, disparities in the provision of student baseline neurocognitive testing are associated with the economic characteristics of the student body. Schools that have a greater proportion of low-income students are less likely to provide comprehensive baseline neurocognitive testing.

- Demographic variation in concussion awareness and knowledge should prompt concerns among policy-makers regarding the effectiveness of concussion policy implementation.

- Healthcare providers have a role in educating parents and their young patients about signs and symptoms of concussion and the management thereof.

both short-term and long-term physical, emotional, cognitive and sleep-related symptoms. ${ }^{45}$ Although individual symptoms can vary, $^{5} 6$ researchers have consistently identified negative effects on academics, ${ }^{7-10}$ physiological functioning, ${ }^{11-14}$ psychological well-being ${ }^{15-17}$ and overall quality of life. ${ }^{18}$

Best practices for managing concussion include education to promote appropriate knowledge, attitudes and behaviours among stakeholders (eg, students, parents, school staff and healthcare providers), ${ }^{19} 20$ interventions to manage recovery ${ }^{2122}$ and protocols to support students returning to academics and school sports. ${ }^{23-25}$ All 50 states have, to varying degrees, codified these best practices in legislation and regulations aimed at preventing and ameliorating concussion symptoms among student-athletes. ${ }^{26}$

Despite widespread student-sports concussion legislation, there is evidence of socioeconomic disparities with respect to the implementation of these laws. One metric for evaluating implementation is awareness and knowledge of concussion and associated risk factors among students and parents. In a study 
that used data from a national sample of athletes ages $12-17$, Donnell et al found that only $55 \%$ of respondents reported having learnt about what to do if they thought that they might have a concussion, and that lower income students were significantly less likely to have learnt about concussion than their higher income peers. ${ }^{27}$ Wallace $e t$ al found that Caucasian high school athletes had greater concussion knowledge and awareness than their African American peers. ${ }^{28}$ Similarly, Bloodgood et al found that African American and Hispanic high school students were significantly less likely to have heard of concussion than Caucasian students, and Hispanic parents were significantly less likely to have heard of concussion than parents of other racial/ethnic backgrounds. ${ }^{29}$ Kroshus et al found that communities with more educated residents were more likely offer flag football, an option that limits tackling contact and thereby reduces the risk of head injury, compared with communities with lesseducated residents. ${ }^{30}$ When students and their parents are not well informed about the symptoms and sequelae of concussion, treatment and appropriate return-toactivity protocols may be delayed or never implemented. Because of the potential adverse neurocognitive effects, it is important that laws and regulations aimed to prevent and manage concussion are evaluated in terms of the feasibility of implementation across different student populations.

A complete baseline neurocognitive assessment evaluates vision, balance and cognitive functioning, as well as for the presence of concussion symptoms before a potential head injury. ${ }^{31}$ Baseline data are compared with postinjury data, and comparisons can aid in informing return-to-activity planning, thereby potentially reducing the risk of long-term sequelae that could impact academic performance, social relationships and emotional well-being. ${ }^{31-33}$ Administration of a baseline assessment requires an interdisciplinary team that may include a trained neuropsychologist, an athletic trainer (AT), a vestibular physical therapist and a sports medicine physician. The use of computerised testing, which primarily addresses cognitive functioning, has become commonplace in non-clinical environments because it can be administered in a time and cost-effective manner by anyone trained to use the software, thereby reducing the degree of clinical involvement and resources required for a complete multifaceted assessment. ${ }^{34}$

In Massachusetts (MA), the provision of computerised baseline neurocognitive testing (BNT) is up to the discretion of each school or school district, and may be dependent on the availability of school resources required for administration. Although administration of computerised BNT is less resource intensive than administration of a complete neurocognitive baseline test, it still requires schools to be well resourced enough to purchase the software, and have qualified personnel available to be trained in administration. Thus, inequitable implementation of BNT may suggest that there are socioeconomic disparities in concussion management resource allocation across MA schools. In a recent survey of MA high school athletic directors (ADs), sponsored by the MA Department of Public Health (MDPH) and conducted by investigators at the Boston Medical Center Injury Prevention Center, about half of high schools provided BNT only for students engaged in extracurricular sports and $18 \%$ did not provide any BNT. In the present study, we used data from this survey to investigate school characteristics associated with the provision of BNT, and assess whether the scope of testing is associated with the economic status of student populations in MA.

\section{METHODS}

\section{Patient and public involvement}

Following focus groups with ADs, the survey was designed to measure ADs' attitudes, practices and beliefs regarding the implementation of MDPH regulations pursuant to the 2010 MA sports concussion law, Chapter 166, An Act Relative to Safety Regulations for School Athletic Programs. This law stipulated that the MDPH develop a concussion prevention and management programme for students participating in extracurricular sports. The programme mandated participation by all MA public schools and any other schools that were members of the Massachusetts Interscolastic Athletic Association (MIAA) ${ }^{34}$ Survey questions were developed in the following categories: (1) characteristics of schools and respondents; (2) salience of the sports concussion law and regulations; (3) concussion diagnosis and management; (4) workload impact of law and regulations; (5) assessment of stakeholder knowledge of law and (6) the extent to which students with concussion misrepresent their symptoms during recovery. The survey was conducted using Qualtrics survey software, licensed to BMC. All ADs ( $\mathrm{n}=346)$ who were employed at schools that are members of the MIAA received an email that introduced the study and contained a link to the questionnaire. The survey was distributed electronically in November 2018, with follow-up to non-respondents in April 2019. The Qualtrics program prohibited more than one response from the same computer. The survey was reviewed and found exempt by the Institutional Review Boards at Boston Medical Center and the MDPH. The survey response rate was $75 \%(260 / 346)$.

\section{Design and sample overview}

Using a cross-sectional design, we conducted secondary analyses of the original survey data to investigate the relationship between school sociodemographic characteristics and the extent to which schools provided students with BNT. School sociodemographic data were derived from the MA Department of Elementary and Secondary Education (DESE) and the Institute of Education Statistics, National Center for Education Statistics (NCES) websites. Our sample included public high schools in MA from which responses to the original AD survey were received. Because the unit of analysis for the present study is the school, rather than individual ADs, when more than one response to this survey was received from 
a single school (because the school employed more than one $\mathrm{AD}$ ), we randomly selected one respondent using the Excel 'remove duplicates' function. Private schools were excluded due to the limited availability of sociodemographic data. After removing duplicate schools from the dataset, 176 independent observations remained, from which 27 private schools were excluded for a final sample of 149 public MA high schools, representing $40 \%$ of all MA public high schools with extracurricular athletic programmes.

\section{Dependent variable}

Scope of baseline testing (TEST)

The scope of BNT was measured using the survey question that asked whether, and for which students, schools provided, 'baseline ImPACT or comparable neurocognitive testing either in person or online'. Response options were: 'none of the students', 'all students engaged in certain extracurricular athletics at the school', 'all students engaged in any extracurricular athletics at the school', 'all students in certain grades', and 'all students in the school'. Responses were ordinally ranked from 0 to 4 , such that none of the students was ranked 0 , and all students in the school was ranked 4 . The survey question did not inquire as to how often schools provided testing to each student.

\section{Independent variables}

Economic disadvantage rate (EDR)

The EDR is the metric used by DESE to describe the socioeconomic status of students enrolled in each school by quantifying the percentage of students whose families meet certain income thresholds. It is based on students' participation in one or more of the following stateadministered programmes: the Supplemental Nutrition Assistance Program, the Transitional Assistance for Families with Dependent Children, the Department of Children and Families' foster care programme and MassHealth (Medicaid). ${ }^{35}$ A higher EDR indicates a greater percentage of low-income students at the school. EDRs for each public high school in our sample were obtained from the DESE website for the 2017-2018 academic school year, the most recent years for which data were available. In 2018, the EDR ranged from 0\%-97.1\% across all MA public schools, and the average EDR was $31.2 \%{ }^{36}$

\section{Athletic trainers (AT)}

Data on whether or not a school employs an AT were derived from the AD survey question, 'Does your school employ an Athletic Trainer?'

\section{Concussion management team (CMT)}

Data on whether a school has a CMT were also derived from the survey. ADs were asked if their school has a CMT comprising school stakeholders (eg, school nurses, ATs, ADs, guidance counsellors and teachers) that meet to manage return to activity (learn and/or play) for students who have experienced a concussion or other head injury.

\section{School size (SIZE)}

Data on school size were derived from the AD survey. ADs were asked how many students were currently enrolled at their school. Response options were 'up to 250' (very small), '251-500' (small), '501-750' (medium), '7511000 ' (large) and 'more than 1,000 ' (very large), and were ordinally ranked from 0 to 5 .

\section{Non-white racial makeup (RACE)}

Data on the racial makeup of students in each school were derived from the NCES website for the 2018-2019 academic school year. Racial makeup was operationalised as the number of students enrolled in the school who were American Indian/Alaska Native, Asian, Black, Hispanic, Native Hawaiian/Pacific Islander, or multiracial, and was calculated by summing the number of students who identify as non-white, and dividing the sum by the total number of students in the school.

\section{School locale (LOCALE)}

The NCES uses the United States Census Bureau data to create a locale classification for each school in the USA. Locale categories include 'city', 'suburb', 'town' and 'rural' and are designated on the basis of proximity to an urbanised area. ${ }^{37}$ Due to a small number of schools in our sample fitting the town criteria, we combined schools in locales designated as town with those designated with rural.

\section{Analytic methods}

We examined collinearity among all continuous independent variables used in our analyses. We conducted bivariate regression analyses to examine the relationship between each independent variable and TEST. We assessed a multivariable linear regression model examining the relationship between EDR and TEST, while controlling for AT and SIZE. We did not include CMT, LOCALE and RACE in the model because CMT and LOCALE were not significantly associated with TEST in bivariate analyses ( $p>0.05)$, and because RACE was highly correlated with EDR. Our alpha level was 0.05. All tests were performed using SAS V.9.4.

\section{RESULTS}

\section{Sample characteristics}

In our sample, $21 \%$ of schools were very small or small, $27 \%$ were medium and $52 \%$ were large or very large; $9 \%$ were urban, $67 \%$ were suburban and $23 \%$ were town/ rural; $77 \%$ employed an AT; $89 \%$ had a CMT; on average, $22 \%$ of students were non-white; and the mean EDR was 19.38 (table 1).

Eighteen per cent of ADs indicated that none of their students receive any $\mathrm{BNT}$ (average $\mathrm{EDR}=24.8 \pm 14.4$ ); $14 \%$ indicated that all students engaged in certain extracurricular athletics at the school receive BNT (average $\mathrm{EDR}=20.9 \pm 16.1) ; 55 \%$ indicated that all students engaged 
Table 1 Demographic characteristics of sample

\begin{tabular}{lcc}
\hline & $\begin{array}{l}\text { Frequency } \\
\text { (number of } \\
\text { schools) }\end{array}$ & Per cent \\
\hline Demographic & & \\
\hline Size (number of students) & 7 & $5 \%$ \\
\hline Up to 250 (very small) & 24 & $16 \%$ \\
\hline $251-500$ (small) & 40 & $27 \%$ \\
\hline $501-750$ (medium) & 26 & $17 \%$ \\
\hline $751-1000$ (large) & 52 & $35 \%$ \\
\hline $1,000+$ (very large) ${ }^{*}$ & & \\
\hline Locale & 13 & $9 \%$ \\
\hline Urban (city) & 99 & $67 \%$ \\
\hline Suburban* & 35 & $23 \%$ \\
\hline Rural & & \\
\hline Athletic trainer & 114 & $77 \%$ \\
\hline Yes & 35 & $23 \%$ \\
\hline No* & & \\
\hline Concussion management team & & \\
\hline Yes & 133 & $11 \%$ \\
\hline No* & 16 & \\
\hline $\begin{array}{l}\text { Average per cent of non-white } \\
\text { students }\end{array}$ & $22 \%$ & \\
\hline Mean EDR score & 19.38 \\
\hline
\end{tabular}

${ }^{*}$ Reference category.

in any extracurricular athletics at the school receive BNT (average $\mathrm{EDR}=19 \pm 10.3$ ); $9 \%$ indicated that all students in certain grades receive BNT (average $\mathrm{EDR}=12.7 \pm 6.2$ ); and, $4 \%$ indicated that all students in the school receive BNT (average EDR=20.9 \pm 19.1 ; table 2 and figure 1).

Table 2 Distribution of baseline neurocognitive testing

\begin{tabular}{lllc}
\hline $\begin{array}{l}\text { Number of } \\
\text { students tested }\end{array}$ & $\begin{array}{l}\text { Frequency } \\
\text { (number of } \\
\text { schools) }\end{array}$ & $\begin{array}{c}\text { Per cent } \\
\text { 土SD }\end{array}$ \\
\hline $\begin{array}{l}\text { None of the } \\
\text { students }\end{array}$ & 25 & $18 \%$ & $24.8 \pm 14.4$ \\
$\begin{array}{l}\text { All students } \\
\text { engaged } \\
\text { in certain }\end{array}$ & 20 & $14 \%$ & $20.9 \pm 16.1$ \\
$\begin{array}{l}\text { extracurriculars } \\
\text { at the school }\end{array}$ & & $55 \%$ & $19 \pm 10.3$ \\
$\begin{array}{l}\text { All students } \\
\text { engaged in any } \\
\text { extracurriculars } \\
\text { at the school }\end{array}$ & 77 & & \\
$\begin{array}{l}\text { All students in } \\
\text { certain grades }\end{array}$ & 13 & & \\
\hline $\begin{array}{l}\text { All students in the } \\
\text { school }\end{array}$ & 5 & $9 \%$ & $12.73 \pm 6.2$ \\
\hline
\end{tabular}

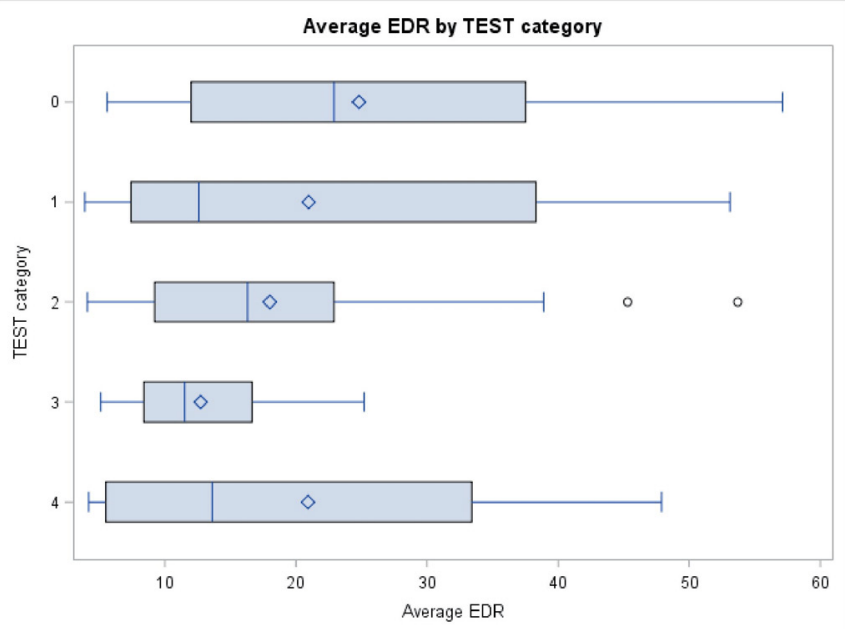

Figure 1 Boxplot of economic disadvantage rate (EDR) by TEST category.

\section{Collinearity analysis}

We evaluated variables for collinearity using Pearson's correlation coefficient for continuous variables (EDR and RACE), and Spearman's ranked correlation coefficient for dichotomous and categorical variables (AT, SIZE, CMT, LOCALE). EDR was independently associated with AT $(\mathrm{r}=-0.18, \mathrm{p}=0.03)$, size $(\mathrm{r}=-0.27, \mathrm{p}=0.001)$ and RACE $(\mathrm{r}=-0.51, \mathrm{p}<0.001$; table 3$)$.

We used bivariate regression to evaluate the association between TEST and each independent variable separately: $\operatorname{EDR}(\beta=-0.02, p=0.01)$; AT $(\beta=0.43, p=0.03)$; and SIZE $(\beta=-0.54, p=0.03)$ were independently associated with TEST. CMT, LOCALE and RACE were not significant independent predictors of TEST ( $p>0.05$; table 4$)$.

\section{Multivariable analyses}

In multivariable regression, EDR was significantly associated with TEST, while controlling for AT and SIZE, such that every $1 \%$ increase in EDR was associated with a 0.01 point decrease in TEST $\left(\beta=-0.01, p=0.03\right.$, adj- $R^{2}=0.1135$; table 5).

\section{DISCUSSION}

Our results suggest that cross-school disparities in the provision of student BNT are associated with the economic characteristics of the student body. Schools that have a greater proportion of low-income students (higher EDR) are less likely to provide comprehensive BNT, and this relationship remains significant when controlling for whether the school employs an AT, and school size. Nevertheless, correlation analysis suggests that the relationship between EDR and BNT is weak. While this finding provides evidence to suggest that there are disparities in the provision of BNT based on economic characteristics of school student bodies, it is not sufficient to suggest that EDR is the primary driver behind schools' decisions or abilities to provide BNT. There are likely other factors, unmeasured in this analysis, that better explain the variance in BNT practices. 
Table 3 Correlation analyses

\begin{tabular}{lllllll} 
& EDR & AT & CMT & Size & Locale & Race \\
\hline EDR & & $-0.18(p=0.03)^{*}$ & $-0.09(p=0.29)$ & $-0.27(p=0.001)^{\star}$ & $0.04(p=-0.60)$ & $-0.51(p<0.001)^{*}$ \\
TEST & $-0.22(0.01)^{\star}$ & $0.18 \dagger(p=0.03)^{*}$ & $0.05 \dagger(p=0.53)$ & $0.06 \dagger(p=0.46)$ & $-0.04(p=0.68)$ & $0.06(p=0.47)$ \\
\hline
\end{tabular}

*Significant at an alpha level of 0.05 .

†Spearman's ranked correlation coefficient.

AT, athletic trainer; CMT, concussion management team; EDR, economic disadvantage rate.

Numerous professional medical groups and international associations have issued guidelines and/or position statements outlining the best practices for sportsrelated concussion management. ${ }^{33} 38-40$ These groups do not identify BNT as a mandatory aspect of concussion management, as there are concerns related to the validity and reliability of computerised tests when they are not administered properly or embedded within larger concussion management programmes. ${ }^{41} 42$ Although we did not assess the quality of BNT administration in our survey, baseline tests can be useful in informing individualised return-to-activity protocols when administered properly. ${ }^{33}{ }^{38-40}$ Moreover, we believe that whether or not a school provides BNT is a useful metric to evaluate the comprehensiveness of school-based concussion management programmes and resources. Our findings are consequential because they indicate that the application of school-based BNT is not uniform state wide: disparities in BNT for student concussion management in MA schools is related to the income level of student bodies.

This finding is problematic because the clinical implications of not receiving a BNT prior to concussion may include diminished quality of postconcussive care, which can have short-term and long-term social, health-related

\begin{tabular}{|c|c|c|}
\hline Independent variable & Beta \pm SE & $P$ value \\
\hline EDR & $-0.02 \pm 0.007$ & $0.012^{*}$ \\
\hline AT & $0.43 \pm 0.2$ & $0.03^{*}$ \\
\hline \multicolumn{3}{|l|}{ Size } \\
\hline Extra small & $0.46 \pm 0.39$ & 0.25 \\
\hline Small & $-0.54 \pm 0.03$ & $0.03^{*}$ \\
\hline Medium & $0.04 \pm 0.21$ & 0.83 \\
\hline Large & $0.15 \pm 0.24$ & 0.54 \\
\hline Extra large & Reference & Reference \\
\hline \multicolumn{3}{|l|}{ Locale } \\
\hline Urban & $0.38 \pm 0.31$ & 0.21 \\
\hline Suburban & Reference & Reference \\
\hline Rural & $0.05 \pm 0.20$ & 0.81 \\
\hline Race (\% white) & $0.32 \pm 0.44$ & 0.47 \\
\hline CMT & $0.22 \pm 0.27$ & 0.42 \\
\hline
\end{tabular}

*Significant at alpha level of 0.05 .

AT, athletic trainer; CMT, concussion management team; EDR, economic disadvantage rate. and educational impacts. Our finding also underscores the contradiction that students least able to financially access private BNT are also least likely to have this service provided by their school.

Nonetheless, our finding is not surprising. Schools that have high proportions of low-income students face complex challenges including but not limited to bullying, ${ }^{43}$ food insecurity, ${ }^{44}$ student and parental chronic stress, ${ }^{45}$ and community and/or family violence outside of school that impact students' mental health and educational attainment. ${ }^{46}$ It is probable that in many schools with high EDRs, limited school resources are prioritised to other student needs. Furthermore, factors including the presence of trained personnel, like an athletic trainer, to administer the test and interpret the scores, access to an interdisciplinary CMT, access to a computer lab and equipment, and access to funds to purchase software influence whether or not a school can provide BNT for students. Many schools in low-income areas are likely unable to administer BNT to all students because of inequitable access to these resources.

At least two studies support our assertion that disparities in concussion management in schools are related to the socioeconomic status of the school's student population, and their access to concussion-management resources, specifically ATs. In a study conducted at secondary schools in Wisconsin, researchers found that schools with a higher proportion of students that qualified for free or reduced lunch (a similar proxy for socioeconomic status as EDR) were less likely to employ an AT, and that students in these schools had less access per week to AT services. ${ }^{47}$ In another study using a national convenience

Table 5 Multivariable analyses predicting scope of baseline neurocognitive testing

\begin{tabular}{lll}
\hline & Beta \pm SE & P value \\
\hline EDR & $-0.01 \pm 0.01$ & $0.03^{*}$ \\
AT & $0.36 \pm 0.25$ & 0.15 \\
Size & & \\
Extra small & $0.83 \pm 0.44$ & 0.06 \\
Small & $-0.26 \pm 0.3$ & 0.38 \\
Medium & $0.09 \pm 0.08$ & 0.68 \\
Large & $0.08 \pm 24$ & 0.74 \\
Extra large & Reference & \\
\hline
\end{tabular}

*Significant at alpha $=0.05$.

AT, athletic trainer; EDR, economic disadvantage rate. 
sample of ATs, researchers found that the most common reasons ATs cited for not employing baseline testing were a lack of money and time. ${ }^{48}$ It is probable that ATs are largely responsible for administering computerised BNTs, so disparities in BNT may be more closely related to a school's ability to employ a full-time AT, and provide ATs with the resources required to administer BNT.

\section{Clinical implications}

Considering ways to promote equitable concussion management and care should be of concern to policymakers, especially because lower income students have less access to routine healthcare compared with their higher income peers. ${ }^{49} 50$ Healthcare providers have a role in educating parents and their young patients about signs and symptoms of concussion and the management thereof, thus increasing access to providers with knowledge of concussion is especially important for students in low-income schools. Systemic changes to healthcare systems, including an expansion of healthcare infrastructure and linguistically appropriate services in low-income communities, are critical to ensure that students in lowincome communities can access such providers outside of school, particularly if their school does not have the resources to provide comprehensive concussion management internally. ${ }^{50} 51$

Differences in concussion awareness and knowledge across the economic spectrum may result in variation in parental pressure on schools to conduct BNT. Wallace et al, Donnell et al, Bloodgood et al and Kroshus et al indicated that concussion-related knowledge varies by income, race and educational attainment. Since most state-level youth concussion legislation contains educational mandates, demographic variation in concussion awareness and knowledge should prompt concerns among policy-makers regarding the effectiveness of policy implementation.

\section{Limitations}

First, our study involved secondary analysis of data from a survey designed to answer questions other than the one investigated herein. The $11.35 \% \mathrm{R}^{2}$ of our regression model suggests that school characteristics not measured by the original survey likely contribute to the provision and scope of BNT. Second, it is possible that our findings understate the strength of the relationship between EDR and scope of BNT because the mean EDR of schools in our sample was lower than that for schools in the state (19.38\% vs $31.2 \%)$. This may be because the state EDR includes special-needs schools that do not have athletic programmes but receive more public funds for services required by their student population. It could also be because schools that have athletic programmes but do not provide baseline testing for their students were less apt to respond to the initial survey and are therefore under-represented in our sample. This would reduce variance in our dependent variable and thereby reduce the robustness of our finding.
Third, the analysis of EDR by impact testing category suggests a dose-response relationship between EDR and the provision and scope of BNT such that as schools' EDR decreases, the provision and scope of BNT increases. The exception among schools that test all students is likely the result of inflated variance due to the small number of schools $(n=5)$ that fall into this testing category. Further analysis with a larger sample of MA schools is warranted. Finally, our study was limited to MA public high schools. Generalisability of our finding to other states should be approached with caution.

\section{CONCLUSION}

This study examined the relationship between socioeconomic status of student populations and the likelihood of students receiving BNT. We found the relationship between EDR and scope of baseline testing to be statistically significant, which has important clinical and social implications. Our findings add to the small but growing literature on disparities in implementation of youth concussion policy and provide sufficient evidence to warrant further investigations. Further study is needed to better understand school-level factors that affect disparities in BNT, and other concussion management practices.

\section{Twitter Julia Campbell @juliakcampbell}

Contributors $\mathrm{JC}, \mathrm{JO}$ and $\mathrm{CH}$ conceived the study design. $\mathrm{JH}$ and $\mathrm{JC}$ acquired the data, and $\mathrm{JH}, \mathrm{JC}$ and $\mathrm{KN}$ analysed and interpreted the data. JC, JH and $\mathrm{CH}$ drafted the manuscript, and RAS, AT, JO and KN contributed substantially to revisions and intellectual content. All authors approve publication of this research, and agree to be accountable for all aspects of the work, including ensuring its accuracy and integrity.

Funding This research was made possible through funding from the Massachusetts Department of Public Health through CDC grant NU17CE924835.

Disclaimer The thoughts and opinions in this report do not necessarily reflect the opinions of the Massachusetts Department of Public Health.

Competing interests None declared.

Patient consent for publication Not required.

Provenance and peer review Not commissioned; externally peer reviewed.

Data availability statement Data are available in a public, open access repository. Data are available upon reasonable request. Data are available in a public, open access repository. Data are available in OSF at: https://osf.io/zydxh/? view_only=243e5062a20d4acf8068386647d39408.

Open access This is an open access article distributed in accordance with the Creative Commons Attribution Non Commercial (CC BY-NC 4.0) license, which permits others to distribute, remix, adapt, build upon this work non-commercially, and license their derivative works on different terms, provided the original work is properly cited, appropriate credit is given, any changes made indicated, and the use is non-commercial. See: http://creativecommons.org/licenses/by-nc/4.0/.

\section{ORCID iD}

Julia Campbell http://orcid.org/0000-0002-2674-1830

\section{REFERENCES}

1 Centers for Disease Control and Prevention. TBI: get the facts. Traumatic brain injury \& concussion, 2019. Available: https://www. cdc.gov/traumaticbraininjury/get_the_facts.html [Accessed 21 Aug 2019].

2 Bryan MA, Rowhani-Rahbar A, Comstock RD, et al. Sportsand recreation-related concussions in US youth. Pediatrics 2016;138:e20154635. 
3 Holmes L, Tworig J, Casini J, et al. Implication of sociodemographics on cognitive-related symptoms in sports concussion among children. Sports Med Open 2016;2:38.

4 Dillard C, Ditchman N, Nersessova K, et al. Post-concussion symptoms in mild traumatic brain injury: findings from a paediatric outpatient clinic. Disabil Rehabil 2017;39:544-50.

5 Kerr ZY, Zuckerman SL, Wasserman EB, et al. Concussion symptoms and return to play time in youth, high school, and college American football athletes. JAMA Pediatr 2016;170:647.

6 Iverson GL, Gardner AJ, Terry DP, et al. Predictors of clinical recovery from concussion: a systematic review. Br J Sports Med 2017;51:941-8.

7 Arbogast KB, McGinley AD, Master CL, et al. Cognitive rest and school-based recommendations following pediatric concussion: the need for primary care support tools. Clin Pediatr 2013;52:397-402.

8 Ransom DM, Vaughan CG, Pratson L, et al. Academic effects of concussion in children and adolescents. Pediatrics 2015; 135:1043-50.

9 Russell K, Selci E, Chu S, et al. Academic outcomes and accommodations following adolescent sport-related concussion: a pilot study. Concussion 2017;2:CNC51.

10 Wasserman EB, Bazarian JJ, Mapstone M, et al. Academic dysfunction after a concussion among US high school and college students. Am J Public Health 2016;106:1247-53.

11 Cantu RC, Gean AD. Second-impact syndrome and a small subdural hematoma: an uncommon catastrophic result of repetitive head injury with a characteristic imaging appearance. J Neurotrauma 2010;27:1557-64.

12 Daneshvar DH, Goldstein LE, Kiernan PT, et al. Post-Traumatic neurodegeneration and chronic traumatic encephalopathy. Mol Cell Neurosci 2015;66:81-90.

13 Grool AM, Aglipay M, Momoli F, et al. Association between early participation in physical activity following acute concussion and persistent postconcussive symptoms in children and adolescents. JAMA 2016;316:2504.

14 Hobbs JG, Young JS, Bailes JE, et al. Sports-related concussions: diagnosis, complications, and current management strategies. Neurosurg Focus 2016;40:E5.

15 Ellis MJ, Ritchie LJ, Koltek M, et al. Psychiatric outcomes after pediatric sports-related concussion. $J$ Neurosurg Pediatr 2015;16:709-18.

16 Gardner A, Iverson GL, McCrory P. Chronic traumatic encephalopathy in sport: a systematic review. Br J Sports Med 2014;48:84-90.

17 Stazyk K, DeMatteo C, Moll S, et al. Depression in youth recovering from concussion: correlates and predictors. Brain Inj 2017;31:631-8.

18 ladevaia C, Roiger T, Zwart MB. Qualitative examination of adolescent health-related quality of life at 1 year postconcussion. $J$ Athl Train 2015;50:1182-9.

19 Caron JG, Bloom GA, Falcão WR, et al. An examination of concussion education programmes: a scoping review methodology. Inj Prev 2015;21:301-8.

20 Caron JG, Rathwell S, Delaney JS, et al. Development, implementation and assessment of a concussion education programme for high school student-athletes. J Sports Sci 2018;36:48-55.

21 McLeod TCV, Lewis JH, Whelihan K, et al. Rest and return to activity after sport-related concussion: a systematic review of the literature. $J$ Athl Train 2017;52:262-87.

22 Reddy CC, Collins M, Lovell M, et al. Efficacy of amantadine treatment on symptoms and neurocognitive performance among adolescents following sports-related concussion. J Head Trauma Rehabil 2013;28:260-5.

23 DeMatteo C, Stazyk K, Giglia L, et al. A balanced protocol for return to school for children and youth following concussive injury. Clin Pediatr 2015;54:783-92.

24 Gioia GA. Medical-school partnership in guiding return to school following mild traumatic brain injury in youth. $J$ Child Neurol 2016;31:93-108.

25 Massachusetts Department of Public Health. Returning to school after concussion. guidelines for Massachusetts schools, 2018. Available: https://www.mass.gov/files/documents/2018/07/ 27/Returning\%20to\%20School\%20After\%20Concussion.pdf [Accessed 21 Aug 2019].

26 National Conference of State Legislatures. Traumatic brain injury legislation. National conference of state legislatures, 2019. Available: http://www.ncsl.org/research/health/traumatic-brain-injurylegislation.aspx

27 Donnell Z, Hoffman R, Sarmiento K, et al. Concussion attitudes, behaviors, and education among youth ages 12-17: results from the 2014 YouthStyles survey. J Safety Res 2018;64:163-9.
28 Wallace J, Covassin T, Moran R. Racial disparities in concussion knowledge and symptom recognition in American adolescent athletes. J Racial Ethn Health Disparities 2018;5:221-8.

29 Bloodgood B, Inokuchi D, Shawver W, et al. Exploration of awareness, knowledge, and perceptions of traumatic brain injury among American youth athletes and their parents. J Adolesc Health 2013:53:34-9.

30 Kroshus E, Sonnen AJ, Chrisman SP, et al. Association between community socioeconomic characteristics and access to youth FLAG football. Inj Prev 2019;25:278-82.

31 Centers for Disease Control and Prevention. FAQs about baseline testing. centers for disease control and prevention, 2016. Available: https://www.cdc.gov/headsup/basics/baseline_testing.html. [Accessed 25 Sept 2019].

32 Covassin T, Elbin RJ, Stiller-Ostrowski JL, et al. Immediate postconcussion assessment and cognitive testing (impact) practices of sports medicine professionals. J Athl Train 2009;44:639-44.

33 Halstead M, Walter K, Moffatt K, American Academy of Pediatrics. Sport-related concussion in children and adolescents, 2018. Available: https://pediatrics.aappublications.org/content/142/6/ e20183074 [Accessed 25 Sept 2019].

34 The General Court of the Commonwealth of Massachusetts. An act relative to safety regulations for school athletic programs, 2010. Available: https://malegislature.gov/Laws/SessionLaws/Acts/2010/ Chapter166 [Accessed 1 Nov 2019].

35 Massachuetts Department of Elementary and Secondary Education. Redefining low Income- a new metric for K-12 education, 2014. http://www.doe.mass.edu/infoservices/data/ed.html

36 Massachusetts Department of Elementary and Secondary Education. Class size by gender and selected population data report. school and district profiles, 2019. Available: http://profiles. doe.mass.edu/statereport/classsizebygenderpopulation.aspx [Accessed 20 Sept 2019].

37 National Center for Education Statistics. School locale definitions. rural education in America., 2006. Available: https://nces.ed.gov/ surveys/ruraled/definitions.asp [Accessed 20 Sept 2019].

38 Harmon KG, Clugston JR, Dec K, et al. American medical society for sports medicine position statement on concussion in sport. Clin J Sport Med 2019;29:87-100.

39 Lumba-Brown A, Yeates KO, Sarmiento K, et al. Centers for disease control and prevention guideline on the diagnosis and management of mild traumatic brain injury among children. JAMA Pediatr 2018;172:e182853

40 McCrory P, Meeuwisse W, Dvořák J, et al. Consensus statement on concussion in sport-the $5^{\text {th }}$ international conference on concussion in sport held in Berlin, October 2016. Br J Sports Med 2017;51:838-47.

41 Echemendia RJ, Iverson GL, McCrea M, et al. Advances in neuropsychological assessment of sport-related concussion. $\mathrm{Br} \mathrm{J}$ Sports Med 2013;47:294-8.

42 Moser RS, Schatz P, Lichtenstein JD. The importance of proper administration and interpretation of neuropsychological baseline and postconcussion computerized testing. Appl Neuropsychol Child 2015;4:41-8.

43 DeVoe JF, Kaffenberger S, Chandler K, US Department of Education, National Center for Education Statistics. Student reports of bullying: results from the 2001 school crime supplement to the National crime victimization survey, 2005.

44 Potamites E, Gordon A. Children's food security and intakes from school meals: final report. Mathematica Policy Research Inc, 2010. https://naldc.nal.usda.gov/download/42320/PDF

45 Schraml K, Perski A, Grossi G, et al. Chronic stress and its consequences on subsequent academic achievement among adolescents. J Educ Develop Psychol 2012;2:p69.

46 Borofsky LA, Kellerman I, Baucom B, et al. Community violence exposure and adolescents' school engagement and academic achievement over time. Psychol Violence 2013;3:381-95.

47 Post E, Winterstein AP, Hetzel SJ, et al. School and community socioeconomic status and access to athletic trainer services in Wisconsin secondary schools. J Athl Train 2019;54:177-81.

48 Williams RM, Welch CE, Weber ML, et al. Athletic trainers' management practices and referral patterns for adolescent athletes after sport-related concussion. Sports Health 2014;6:434-9.

49 Lazar M, Davenport L. Barriers to health care access for low income families: a review of literature. $J$ Community Health Nurs 2018;35:28-37.

50 Zhu J, Brawarsky P, Lipsitz S, et al. Massachusetts health reform and disparities in coverage, access and health status. J Gen Intern Med 2010;25:1356-62.

51 Smedley BD. Moving beyond access: achieving equity in state health care reform. Health Aff 2008;27:447-55. 